\title{
User statistics for CD-ROM selection and management
}

\section{By Karyle S. Butcher and Shirley R. Scott}

\section{Good data aids collection decisions}

A $\mathrm{n}$ academic library entering the CD-ROM (CD) arena may anticipate the popularity of $\mathrm{CD}$ access for its users and the increased visibility it may bring to the library on campus. ${ }^{1}$ Such library services as online searching, bibliographic instruction, and interlibrary loan will be affected by the addition of this technology. ${ }^{2}$ Moreover, several important management issues must also be considered. A statistical program can be useful in resolving these issues; this is especially true for those decisions which revolve around staffing and collection management. This paper addresses the usefulness of CD-ROM user statistics in making selection/ deselection decisions and in managing a CDROM installation. Included is reference to the authors' experience.

\section{Statistics management}

In 1987 the Oregon State University (OSU) Libraries established a 12 -station $\mathrm{CD}$ reference center. Our belief when we established the center was that it would be used widely by undergraduates and graduates and that as its use increased, other library services and collections would be affected. To see if this was true, we developed a simple system which allowed us to track usage. The system required users to sign in and indicate their academic status and which databases they intended to search. Statistics were totaled monthly or as time allowed. As usage increased, we moved to a more sophisticated statistics-keeping program. In 1990 the library purchased menuing software from Saber Software Corporation to manage record-keeping and to customize the menu format. Data is now recorded automatically as the user logs onto the $\mathrm{CD}$ workstation or network. The program allows for the creation of a dBase data file which can then be analyzed by a program written by our CD librarian.

The software captures all menu choices into the dBase file as well as time logged in and out, and includes an automatic logoff function. Although we do not presently restrict off-campus users who access our CD network, the Saber software provides options for passwords and limitations on the number of users of a particular application. It also has the potential for providing help screens for users at remote sites.

The setup is configured so that the initial menu screen is the login screen. Here, the user chooses either the local drives or networked databases. Because the system requires a different login prompt for each location, the software allows us to know whether a user is in the library or outside the library. Local and networked databases are listed on separate menus, thus informing offsite users that the library has databases which are not available on the network. After selecting a database, users are required to indicate their group status (freshman, sophomore, junior, senior, graduate, faculty, staff, other) before going to the next screen, which requests department or other affiliation. Next is a seven-subject menu. The final menu is a database list appropriate to the subject area chosen.

The information provided by this program is useful for many management and research purposes. We have analyzed use statistics to determine when the center is most heavily used and have reduced staff hours during slow periods and increased staffing at busy times. The program tells us who our users are and which 
databases they are using. Analysis of this information helps us to determine whether users are selecting the appropriate databases for their indicated subject interests. If, for example, we determine that graduate students in agriculture are using the General Science Index instead of Agricola, we will emphasize in our library instruction courses the difference between the two. In addition, it provides information on the average time a user searches a database, allowing us to know how often and how long each database is used per hour, per day, per week, and per month. We are able to determine the cost per search of each database, and have used this information in budget presentations to the university administration.

\section{Collection management}

User statistics are also helpful in making collection management decisions. The increase of information on CDs and declining budgets are forcing libraries to look at a variety of methods for making collection management decisions. Libraries must balance the decision to purchase CDs with that of purchasing materials in traditional formats. A statistical package can be useful in making these decisions

At OSU, the initial selection of databases was accomplished by librarians who recommended purchases in their subject areas. Since that time, the $\mathrm{CD}$ librarian has established a demonstration workstation in the reference office on which databases are previewed and evaluated by librarians and other campus faculty. The librarians use a revised version of the selection criteria outlined by Nancy Herther and Irene Hoffman ${ }^{3}$ and make recommendations for purchase. Because a stagnant materials budget has determined that we can add no new serials subscriptions without canceling old ones, purchase decisions cause heated debate among the librarians responsible for collection development.

We developed a series of steps to follow to aid in making selection and deselection decisions for paper and CD formats. Included in this procedure is a comparison of the cost and usage statistics for those databases on $C D$ with the paper copies. Such analysis covers the cost of the paper index versus the CD cost, the scope of coverage, and information on who uses the databases, i.e, undergraduates, graduates, or faculty.

To determine how we could improve our current $\mathrm{CD}$ collection, the $\mathrm{CD}$ librarian analyzed the overlap in titles indexed for a number of our subject-related databases and compared costs of retaining indexes in both print and $\mathrm{CD}$ formats. The cost of the print version for some indexes, especially the Wilson indexes, is often comparable to or more than the $C D$ version. Using this information as well as usage statistics, the subject librarians make recommendations for canceling paper or $\mathrm{CD}$ copies of the indexes. With the savings from cancellations of one copy of indexes in duplicate formats, we have purchased additional $\mathrm{CD}$ databases.

\section{Conclusion}

Purchasing information in electronic formats such as CD-ROM can be difficult due to decreasing budgets and the need to maintain traditional formats. Yet, increasingly sophisticated library users request the ease of using electronic formats. How to evaluate the use and cost of databases on $\mathrm{CD}$ with those in print format? If paper sources are dropped are some users being disenfranchised? How are these decisions to be made?

Using available software programs, collection and analysis of user statistics are helpful in making these decisions. Such programs allow for the collection of data on use, level of user, choice of database, and amount of time spent searching. This information can be applied to determine use and staffing patterns for CD installations and allow the library to make adjustments accordingly. Selection and cancellation decisions are also made easier using data gathered on use, cost, and scope of coverage. Knowing comparative costs, who the users are, and what they are using allows the opportunity to make enlightened decisions.

\section{Notes}

'Carol Tenopir, "The Impact of CD-ROM on Online," Library Journal 116 (Feb. 1991): 61-62.

${ }^{2}$ Karyle Butcher and Shirley Scott, "Effects of CD-ROM in a University Library," Journal of Educational Media E Library Sciences 27:3 (Spring 1990): 257-69.

${ }^{3}$ N. K. Herther, "How to Evaluate Reference Materials on CD-ROM," Online 12 (March 1988): 106-08; Irene M. Hoffman, "CD-ROM Planning Checklist; Collection Development Resource/ Organization/Management," address given at an OCLC Preconference, "CD-ROMBO: Combat and Compromise." Annual Conference of the Oregon Library Association, April 5, 1989, Sunriver, Oregon. 


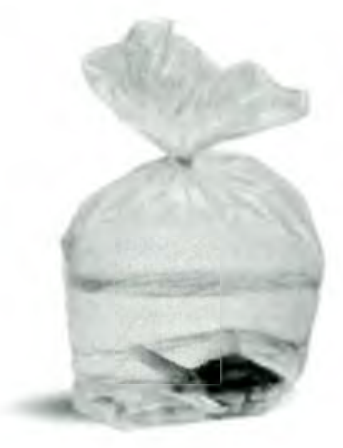

The small customer.

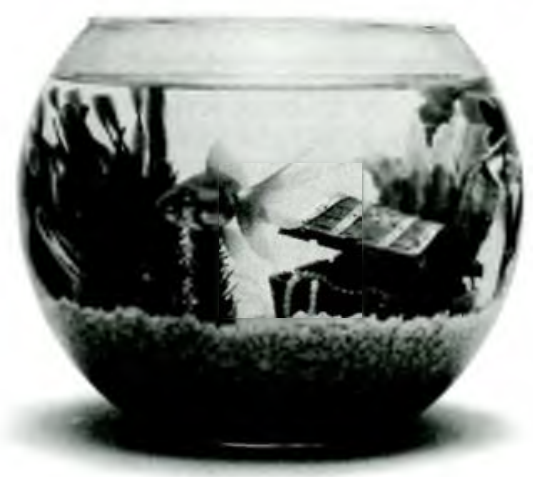

The small customer at Ballen.
With some booksellers, a small customer doesn't rate quite the consideration that a large customer might. But at Ballen, the single book customer receives the same service and services that a thousand book customer does.

Which means no matter what size your library, you can expect to have your very own customer service representative to help answer all your questions. And your very own shelf reserved in our warehouse to guard against shipment and inventory mix-ups.

It also means access to our online, interactive BallenNet system for order entry and current status. The ability to reach a Ballen company officer just by picking up the phone. And an ongoing evaluation of library needs so rigorous, it's given us the industry's lowest overall return rate - less than $1 \%$.

All of which we provide with the understanding that what are small fish today, might one day be big ones.

For information or our new brochure, call (800)645-5237.

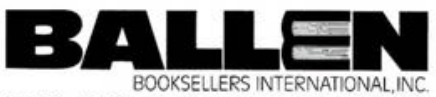

125 Ricefield Lane, Hauppauge, New York 11788 